\title{
Empirical Research on FDI Introduction Effects on Carbon Emissions the in Jiangsu Province on the Background of Demonstration Zone of South Jiangsu
}

\author{
Ming YAN \\ Low Carbon Economy Research, Hohai university, Changzhou, Jiangsu, China \\ Ze TIAN \\ Low Carbon Economy Research, Hohai university, Changzhou, Jiangsu, China
}

\begin{abstract}
The construction of South Jiangsu modernization demonstration area bring an opportunity to build an ecological civilization of Jiangsu, while more reflected in the constraints of environmental system. Based on the system analysis of the introduction of FDI carbon of scale, structure, regulation and technology effect in Jiangsu Province, this paper utilizes year 2002 to 2012 statistical data to calculate the carbon emissions effects of FDI introduction in Jiangsu through KAYA model and simultaneous equations model, and applies the unit root test and Engel - Grainger two step test to prove that there is a co-integration relationship between the introduction of FDI in Jiangsu and carbon emission. Then it proves the environmental impacts on introduction of FDI through 4 effects. The results show that the introduction of FDI in Jiangsu has a positive effect on the reduction of carbon emissions. Therefore this article put forward some corresponding advice to protect ecological environment effectively.
\end{abstract}

KEYWORD: The construction of demonstration zone; Introduction of FDI; Carbon emission effects; Simultaneous equations model

\section{INTRODUCTION}

\subsection{Background}

As a big province to attract foreign investment, Jiangsu is in the leading position in terms of economic development and opening up. Recent years Jiangsu got not only a large number of capital needed for economic construction through the introduction of foreign direct investment (refer to as FDI), but also foreign advanced technology and management talents with abundant experience, which gave a tremendous push to its economic development and industrial transition. With the introduction of FDI moving fast, some high energy consumption, high pollution and high carbon industries started to transfer into Jiangsu from developed countries, which caused many problems such as ecological environment worsen gradually, excessive energy consumption and sharply increasing $\mathrm{CO}_{2}, \mathrm{SO}_{2}$ emission that intensified the contradiction between introduction of FDI and environmental protection.

South Jiangsu Modernization Demonstration Area Planning appeal that we must set up a new mode to make economic development, ecological civilization and environmental protection harmonious development. Thus it is a essential topic for discussion that how to coordinate the relation between introduction of FDI and environmental protection, and correctly estimate the FDI introduction effects and influence on the carbon emission in Jiangsu province.

\subsection{Reviews of research at home and abroad}

Nowadays capital flows become frequent among countries. And trade barriers were gradually put down. Meanwhile, it also brought about high energy consumption, high pollution and high carbon problem in some degree. Some foreign scholars did deep research on FDI introduction effects on the carbon emission based on the hypothesis of Pollution Havens, Environment Kuznets Curve and Pollution Halo[1].

Grossman \& Krueger (1991) analyzed the situation of NAFTA and proposed the Emissions decomposition formula :

$P=Y \sum S_{n} I_{n}$

where $P=$ Pollution emissions; $\mathrm{Y}=$ Total output; $\mathrm{I}_{\mathrm{n}}=\mathrm{n}$ industry's pollution emissions; $\mathrm{S}_{\mathrm{n}}=$ Total output proportion of $n$ industry.

It revealed three factors on carbon emission effects on the FDI introduction: economy scale, structure and technology level. According to the fact Panayotou (1997) added a control effect[2]. N. 
Mabey \& R. Mcnally (1999) thought that the carbon emission effects on the FDI introduction is complex. On one hand, it brought host country advanced cleaning technology and management level to improve the environment. On the other hand, FDI now often transport its Pollution-intensive industries from developed to developing countries so that it did harm to the environment of host country unavoidable. Kevub Grey \& Duncan Brank (2002) proposed the Pollution Halo effect, he pointed out that FDI bring in high technology and management so as to improve the control regulation and then make the environment better.

In terms of empirical research, most scholars applied the model of LMDI, KAYA, STIRPAT to calculate the regional carbon emission. And then utilized the method of Multivariate Regression Analysis, Grey Relational Analysis and Simultaneous Equations Models to do the research indepth. Jie He (2006) applied Simultaneous Equations Models with the environmental data of 29 provinces in China, regarding $\mathrm{SO}_{2}$ emission as environmental pollution characterization, to estimate the FDI introduction direct and indirect effects on the carbon emission in terms of scale, structure and technology. For Chinese scholars' research, Yi Yanchun (2011) emphasized the technology spillover effect, especially focused on FDI flown into manufacture industry, which could reduce carbon emission through structure and technology effects. But $\mathrm{Hu}$ Jiayu (2011) discussed the four effects' relation between the introduction of FDI and carbon emission in China. It was concluding that the introduction of FDI and carbon emission in China had a Significant positive correlation. And energy saving and emission reduction effect of the Chinese was not significant.

\section{THEORETICAL ANALYSIS}

According to the former achievements, such as Grossman \& Krueger and $\mathrm{Jie} \mathrm{He}$, we divided the FDI introduction effects on the carbon emission into four parts below.

\subsection{Environment Kuznets Curve \& Scale effect}

Scale effect is the environmental impact of economic scale changes caused by the scale of FDI introduction changes. These changes are described vividly by Environment Kuznets Curve.

It is a fact that part of developed countries took a half century after industrialization to recover the environment. Some experts predicted that China will have a "inflection point" near the year of 2020 according to the relation between Euro-United States per capita GDP and environmental inflection point. For Jiangsu province, per capita GDP amounted to
12047 US dollars, which leaded the whole country and nearly caught up with the rich countries level.

\subsection{Government \& Control effect}

Control effect is that the policies of host country government impact on the FDI introduction. In the common trade terms, developed countries have a relatively strict environmental regulation measures, but developing countries have relatively loose environmental regulation policy. Thus developed countries transfer their pollution intensive industries to developing countries where there is relatively loose environmental regulation policy.

A large number of FDI introduction gave Jiangsu more stable cash flows. At the same time, it more or less leads to some serious environment problems, such as fog and haze, Taihu Lake water pollution and poisonous chemical smoke event, which will be harmful for our life quality. It is obvious that foreign high-polluted companies coming into Jiangsu have made a series of pessimistic impacts on environment.

So at the background of national ecological civilization construction and South Jiangsu Modernization Demonstration Area Planning, government has issued some necessary regulation, which emphasized that we must reinforce the regulation of ecological space, push forward the ability of sustainable development in economic society, and applause the low carbon environmental protection knowledge for setting a example to the nation.

\subsection{Structure effect}

Structure effect is that regional distribution and Industry composition of FDI introduction impact on the environment of host country. According to the industrial structure of Jiangsu, primary industry scale is expanding, but its total amount is still small; Investment of tertiary industry is now weighted in real estate, which cause developing unbalance in the industry; and FDI mainly focus on the secondary industry, especially in heavy industry and manufacturing industry, but the good news is that the proportion of high-polluted industries is decreasing.

For regional distribution of FDI introduction in Jiangsu, there has been a progressive decrease from Southern, central to the northern so that the regional development unbalance.

\subsection{Creative \& Technology effect}

Technology effect is that technology progress, spread and assignment led by investment liberalization impact on the environment. FDI introduction of High-tech and low carbon can bring in environmentally friendly production technology and process management level, which will benefit for improving 
the living environment and quality of production. Jiangsu increase energy utilization through the full implementation of clean production to improve the balance development between economy and environment.

\section{EMPIRICAL RESEARCH}

\subsection{Econometric model building}

Based on carbon emissions measurement model by Yoichi Kaya (1989) and Chinese reality, this paper used deformation formula to calculate the total amount carbon emission from the year 2002 to 2012, and simultaneous equations model to estimate the FDI introduction effects on the carbon emission in Jiangsu province.

\subsubsection{Kaya model}

$$
C=\sum_{i} C_{i}=\sum_{i} \frac{C_{i}}{E_{i}} \times \frac{E_{i}}{E} \times \frac{E}{Y} \times \frac{Y}{P} \times P
$$

where $\mathrm{C}=$ total amount carbon emission; $\mathrm{C}_{\mathrm{i}}=$ carbon emission in energy $\mathrm{i}$; $\mathrm{E}=$ primary energy consumption; $\mathrm{E}_{\mathrm{i}}=$ energy i's consumption; $\mathrm{Y}=$ GDP; and $\mathrm{P}=$ population.

\subsubsection{Carbon emission deformation model}

$$
C=\sum_{i} S_{i} \times F_{i} \times E
$$

where $\mathrm{C}=$ total amount carbon emission; $\mathrm{S}_{\mathrm{i}}=$ Total energy consumption proportion of $\mathrm{i}$ industry; $\mathrm{E}$ = primary energy consumption; and $\mathrm{F}_{\mathrm{i}}=$ energy I's carbon intensity.

\subsubsection{Environment effect analysis model}

$C=\alpha_{1}$ Gdp $+\alpha_{2}$ Fdi $+\alpha_{3}$ Govern $+\alpha_{4}$ Structure $+\alpha_{5}$ Tech $+c_{1}+\varepsilon_{1}$ $G d p=\alpha_{6} C+\alpha_{7} F d i+\alpha_{8}$ Capital $+\alpha_{9}$ Labor $+c_{2}+\varepsilon_{2}$

Structure $=\alpha_{10} G d p+\alpha_{11} F d i+\alpha_{12}$ Capital / Labor $+c_{3}+\varepsilon_{3}$

Govern $=\alpha_{13} C+\alpha_{14} F d i+\alpha_{15}$ Tech $.+\alpha_{16} G d p+c_{4}+\varepsilon_{4}$

Tech. $=\alpha_{17} G d p+\alpha_{18} F d i+\alpha_{19} R D+c_{5}+\varepsilon_{5}$

In order to remove heteroscedasticity in data, we transferred above variable into logarithm, and got the simultaneous equations model below[3]:

$$
\begin{aligned}
& L n C=\alpha_{1} L n Y+\alpha_{2} L n F+\alpha_{3} L n G+\alpha_{4} L n S+\alpha_{5} L n T+c_{1}+\varepsilon_{1} \\
& L n Y=\alpha_{6} L n C+\alpha_{7} L n F+\alpha_{8} L n K+\alpha_{9} L n L+c_{2}+\varepsilon_{2} \\
& L n S=\alpha_{10} L n Y+\alpha_{11} L n F+\alpha_{12} L n K / L^{+} c_{3}+\varepsilon_{3} \\
& L n G=\alpha_{13} L n C+\alpha_{14} L n F+\alpha_{15} L n T+\alpha_{16} L n Y+c_{4}+\varepsilon_{4} \\
& L n T=\alpha_{17} L n Y+\alpha_{18} L n F+\alpha_{19} L n R D+c_{5}+\varepsilon_{5}
\end{aligned}
$$

where $\mathrm{C}=$ total amount carbon emission; $\mathrm{Y}=$ GDP; $\mathrm{F}=$ FDI introduction; $\mathrm{G}=$ Government control; $\mathrm{S}=$ Structure $; \mathrm{T}=$ Technology $\mathrm{K}=$ Capital; $\mathrm{L}=$ Labor; $\mathrm{RD}=$ Research \& Development fees.

Formula (3.3) is carbon emission comprehensive formula. It is a direct impact that includes Scale, Govern, Technology, Structure and FDI factors. $\mathrm{C}_{\text {Scale }}, \mathrm{C}_{\text {Govern }}, \mathrm{C}_{\text {Technology }}, \mathrm{C}_{\text {Structure }}$ and $\mathrm{C}_{\mathrm{FDI}}$ are used for representing above factors.

Formula (3.4) is carbon emission scale formula. It is a direct impact for FDI to economic scale. And $\mathrm{C}_{\text {Scalex }} \mathrm{Y}_{\mathrm{FDI}}$ is used to represent it.

Formula (3.5) is carbon emission structure formula. On one hand, it is a direct impact for FDI to economic structure. On the other hand, FDI introduction adjust industrial structure through changing the economic scale, so $\mathrm{C}_{\text {Structure }} \times \mathrm{S}_{\mathrm{FDI}}$ and $\mathrm{C}_{\text {Structure }} \times \mathrm{S}_{\text {Scale }} \times \mathrm{Y}_{\mathrm{FDI}}$ are used to represent them.

Formula (3.6) is carbon emission govern formula. It is a direct impact for FDI to government controlling. What's more, FDI introduction improves the technology progress, and then has a indirect impact on government control effect. so $\mathrm{C}_{\text {Govern }} \times \mathrm{G}_{\mathrm{FDI}}$ and $\mathrm{C}_{\text {Govern }} \times \mathrm{G}_{\text {Technology }} \times \mathrm{T}_{\mathrm{FDI}}$ are used to represent them.

Formula (3.7) is carbon emission technology formula. It is a direct impact for FDI to technology progress. Besides FDI is also introduced to $R \& D$ area, and then indirectly achieve technology revolution. So $\mathrm{C}_{\text {Technology }} \times \mathrm{T}_{\mathrm{FDI}}$ and $\mathrm{C}_{\mathrm{Technology}} \times \mathrm{T}_{\mathrm{RD}}$ are used to represent them.

Above all, results of formula (3.4) to (3.7) add up to the total FDI introduction effects on the carbon emission in Jiangsu.

\section{RESULTS}

\subsection{Estimation of total carbon emissions}

This paper chose the energy consumption data in Jiangsu from 2002 to 2012 with the Carbon emission deformation model. We can get the result in the line chart below.

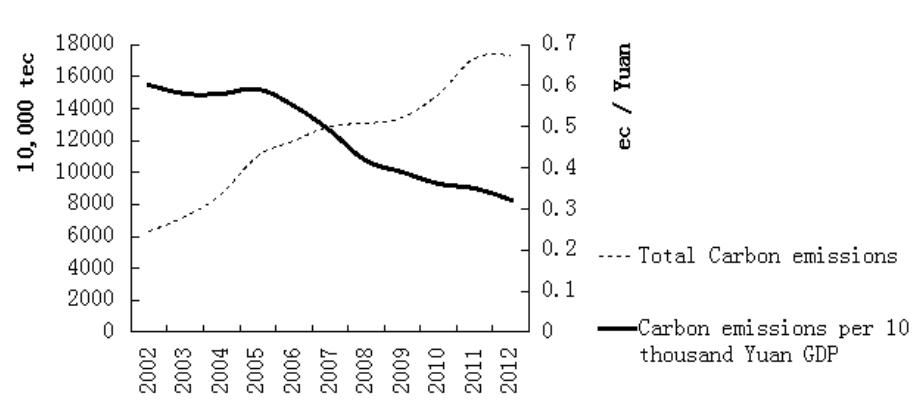

Fig. 1 Carbon emissions in Jiangsu (2002-2012)

According to the result above, we can conclude that total carbon emission is still increasing, but the trend has been slowed. Compared with year 2002, Jiangsu Carbon emissions per 10 thousand Yuan GDP in 2012 nearly Cut in half, which indicate that 
energy saving and emission reduction work achieved good results in Jiangsu.

\subsection{Result of simultaneous equations model}

We applied the unit root test and Engel - Grainger two step test to prove that there is a co-integration relationship between the introduction of FDI in Jiangsu and carbon emissions. After considering whether the model exist auto-correlation or not, we made some revise and got the final model below:

Tab. 1 The estimation results of the introduction of FDI effect on carbon emissions in Jiangsu

\begin{tabular}{|c|c|c|c|c|}
\hline Formulas & Variables & Coefficients & Variables & Coefficients \\
\hline \multirow{3}{*}{$\mathrm{C}$} & $\mathrm{C} 1$ & -7.346 & $\alpha 3$ & -0.579 \\
\cline { 2 - 5 } & $\alpha 1$ & 0.305 & $\alpha 4$ & 3.041 \\
\cline { 2 - 5 } & $\alpha 2$ & -0.086 & $\alpha 5$ & 0.441 \\
\hline \multirow{4}{*}{$\mathrm{Y}$} & $\mathrm{C} 2$ & -1.070 & $\alpha 8$ & 0.703 \\
\cline { 2 - 5 } & $\alpha 6$ & 0.222 & $\alpha 9$ & 0.487 \\
\cline { 2 - 5 } & $\alpha 7$ & -0.054 & & \\
\hline \multirow{4}{*}{$\mathrm{S}$} & $\mathrm{C} 3$ & 5.772 & $\alpha 12$ & -0.029 \\
\cline { 2 - 5 } & $\alpha 10$ & -0.116 & $\mathrm{AR}(1)$ & 0.79 \\
\cline { 2 - 5 } & $\alpha 11$ & -0.008 & & \\
\hline \multirow{3}{*}{$\mathrm{G}$} & $\mathrm{C} 4$ & 4.479 & $\alpha 15$ & -0.009 \\
\cline { 2 - 5 } & $\alpha 13$ & -0.389 & $\alpha 16$ & 0.172 \\
\cline { 2 - 5 } & $\alpha 14$ & 0.012 & $\alpha 14$ & 0.012 \\
\hline \multirow{2}{*}{$\mathrm{T}$} & $\mathrm{C} 5$ & -8.836 & $\alpha 18$ & -0.088 \\
\cline { 2 - 5 } & $\alpha 17$ & 1.860 & $\alpha 19$ & -0.671 \\
\hline
\end{tabular}

From the results, we can conclude some points:

In terms of industrial structure, the proportion of the second industry increased by $1 \%$, while the carbon emissions increase by $3.04 \%$. It is the biggest impact that the proportion of the second industry in Jiangsu has on carbon emission.

The expansion of national economy is caused by increased accumulation of capital, labor population and the growth of carbon emissions. The accumulation of capital makes the largest contribution to the growth of GDP.

FDI introduction can push forward the level of national economy, and help industrial structure to be adjusted and optimized. Nowadays the proportion of the second industry FDI is decreasing in Jiangsu, which leads a bigger development space to the first and the third industry.

The government control effect is negatively correlated with the growth of carbon emissions. What's more, the growth of FDI and GDP can raise the govern and supervise level in Jiangsu.

Based on the conclusion above, we can list the effects on carbon emission below:

$\mathrm{C}_{\mathrm{FDI}}=-0.086 ; \mathrm{C}_{\mathrm{Scale}} \times \mathrm{Y}_{\mathrm{FDI}}=-0.017$;

$\mathrm{C}_{\text {Structure }} \times \mathrm{S}_{\mathrm{FDI}}=-0.025 ; \mathrm{C}_{\text {Structure }} \times \mathrm{S}_{\text {Scale }} \times \mathrm{Y}_{\mathrm{FDI}}=0.019$;

$\mathrm{C}_{\text {Govern }} \times \mathrm{G}_{\text {Technology }} \times \mathrm{T}_{\mathrm{FDI}}=-0.0004$;

$\mathrm{C}_{\text {Govern }} \times \mathrm{G}_{\mathrm{FDI}}=-0.007 ; \mathrm{C}_{\text {Technology }} \times \mathrm{T}_{\mathrm{FDI}}=-0.039$;
$\mathrm{C}_{\text {Technology }} \times \mathrm{T}_{\mathrm{RD}}=-0.296$ 。

So the FDI introduction comprehensive effect on carbon emission is -0.4514 . That is to say, carbon emission will decrease by $0.45 \%$, when FDI introduction increase by $1 \%$.

\section{MEASURES}

First, we must carry out strict environmental access system, and introduce high level of low carbon foreign investment enterprises and projects. It is important for FDI introduction to blend into the modern industrial system whose core is modern service industry and advanced manufacturing in Jiangsu.

Secondly, Based on demonstration zone and ecological civilization construction, government must strengthen the supervision of foreign investment environment, push more ahead EMC projects, attract new energy and clean production foreign enterprise, and combine to construct an ecological civilization city group.

Third, Jiangsu must improve the level of FDI introduction to optimize the industrial structure of FDI. Besides we should keep FDI projects and foreign enterprise be energy conservation and environment protection so that the industrial structure of Jiangsu become reasonable.

Fourth, Jiangsu must optimize the regional distribution of FDI introduction so that it can promote the southern and northern coordinated development. We can develop competitive ability of differentiation to achieve dislocation development, complementary advantages among the south, north and central of Jiangsu.

\section{ACKNOWLEDGEMENT}

This paper is supported by: 1) Foundational Research Funds for the Central Universities of Hohai University (Grant No. 2013B19414 and Grant No.2013B30614). 2).Hohai University Changzhou campus graduate technical innovation project.

\section{REFERENCES}

[1] Jensen V.1996.The Pollution Haven Hy-pothesis and Industrial Flight Hypothesis: Some Perspectiveson Theory and Empirics. Work Paper, Centre for Development, University of Oslo.

[2] Panayotou T.1997.Demystifying the environmental Kuznets curves: turning a black box into a policy tool. Ecological Economics, 38(3):359-367

[3] Jie He. 2006. Pollution haven hypothesis and environmental impacts of foreign direct investment: The case of industrial emission of sulfur dioxide $(\mathrm{SOz})$ in Chinese provinces. Ecological Economics, 60(1): 228-245. 